\title{
Makespaces: From Redistributed Manufacturing to a Circular Economy
}

\author{
Sharon Prendeville ${ }^{1,2}$, Grit Hartung ${ }^{2}$, Erica Purvis ${ }^{2}$, Clare Brass ${ }^{2}$, Ashley Hall ${ }^{2}$ \\ ${ }^{1}$ Product Innovation Management, Industrial Design Engineering, TU Delft, Landbergstraat 15, \\ 2628 CE, The Netherlands. \\ ${ }^{2}$ SustainRCA, Royal College of Art, Kensington Gore, London SW7 2EU \\ E-mail: S.M.Prendevilledtudelft.nl
}

Keywords: Redistributed Manufacturing, Circular Economy, Design, Making

\begin{abstract}
Redistributed manufacturing is an emerging concept which captures the anticipated reshoring and localisation of production from large scale manufacturing plants to smaller-scale localised, customisable production units, largely driven by new additive digital production technologies. Critically, community-based digital fabrication workshops, or makespaces, are anticipated to be the hothouse for this new era of localised production and as such are key to future sustainable design and manufacturing practices. In parallel, the concept of the circular economy (CE) conceptualises the move from a linear economy of takemake-waste to a closed loop system, through repair, remanufacturing, refurbishment and recycling which maintains the value of materials and resources.

Despite the clear interplay between RdM and CE, there is limited research exploring this relationship. In light of these interconnected developments, the aim of this paper is to explore the role of makespaces in contributing to a circular economy through RdM activities. This is achieved through six semistructured interviews with thought leaders on these topics. The research findings identify barriers and opportunities to both CE and RdM, uncovers key overlaps between $\mathrm{CE}$ and $\mathrm{RdM}$, and identifies a range of future research directions that can support the coming together of these areas.

The research contributes to a wider conversation on embedding circular practices within makespaces and their role in RdM.
\end{abstract}

\section{Introduction}

In its vision for manufacturing in 2030, the EU (2015) identifies megatrends of mass customisation, flexible, responsive, personalised and integrated (in homes) manufacturing, enabled by metropolitan manufacturing ecosystems which are built through the digitisation and virtualisation of society, as well as diffusion of new technologies. Such digitisation is an enabler for Redistributed Manufacturing (RDM), which sees a move away from centralised production facilities, towards local manufacturing and use of digital technologies leading to shortened supply chains and thereby reduced

adfa, p. 1, 2011.

(C) Springer-Verlag Berlin Heidelberg 2011 
transport. In doing so, RDM is expected to reduce environmental impacts and wastes (through additive technologies) and energy consumption of production through shortened supply chains (WEF, 2015). Critically, community-based digital fabrication workshops, or makespaces, are anticipated to be the hothouse for this new era of localised production and as such are key to future sustainable design and manufacturing practices.

In parallel, the concept of the circular economy (CE) conceptualises the move from a linear economy of take-make-waste to a closed loop system (Ellen Macarthur, 2014) through repair, remanufacturing, refurbishment and recycling, to maintain materials and resources in a closed cycle. Its integration in international policies from China, through its 11th and 12th 'Five Year Plans' (Su et al., 2013), to Europe through its Circular Economy Roadmap (European Commission, 2014) reflect its ever increasing appeal. Despite the clear interplay between RDM and CE, there is limited research exploring this relationship. In light of these interconnected developments, the aim of this paper is to explore the role of makespaces in contributing to a circular economy through redistributed manufacturing activities.

\section{$2 \quad$ Literature Review}

\subsection{The Emergence of Makespaces}

Community-based digital fabrication workshops, or makespaces, are vastly diverse (Hielscher \& Smith, 2014), creative and social places where makers can network, learn and access a variety of (previously inaccessible) fabrication tools and technologies. Despite limited research on the characteristics and activities of makespaces in general, some studies exist (see: Hielscher \& Smith, 2014). Understanding the activities and structures of makespaces is important, given the range of activities underway, disparate governance structures, scope of ambitions, and diversity of local contexts (Hielscher \& Smith, 2010). Troxler (2010) devised a framework to interpret the diversity of makespaces, from tech shops, to sharing platforms, Fab Labs, and hackerspaces spanning activities from open hardware design to repair workshops. Indeed, some say that, through the act of making itself, the new 'prosumer' can foster a connection with the object being made (Kohtala \& Hyysalo, 2015) and therefore a longer product life is expected.

Nonetheless, at the heart of many maker communities are values that relate to sustainability. 'A third place', Kohtala (2014) identifies the tendency to collaborate openly, to adopt industrial ecology principles, to focus on local problems, and to draw on a needs-based solutions. Makespaces are defined by local values, openness and freeness, Gershenfeld, (2005); collaboration and sharing (Thakkara, 2010); respect for resources and cultural assets Kohtala (2014). However, Kohtala (2014) also states that socio-economic imperatives (short-term survival) mean environmental issues are not given much concern. 


\subsection{Re-distributed Manufacturing (RdM)}

While there are common threads clear consensus on what RDM actually entails and its benefits have yet to be determined. The EPSRC (2013) identify: local manufacturing for local communities and economies; cloud manufacturing services; dynamic production environments capable of creating customisable or multi-variant products; sustainable/resource efficiency; and flexibility/agility in production suited to short ramp-up times as key characteristics of RDM. Table 2 presents a list of definitions of RdM reflecting these characteristics and more.

One catalyst for the increase in makespaces globally, is the diffusion of technologies such as additive manufacturing. These new technologies are purported to contribute to emissions and energy use reductions. For example, Gebler et al. (2014) claim, with somewhat large deviations, that 3D-printing has the potential to reduce costs (for companies) by 170-593 billion dollars (US), the total primary energy supply by $2.54-9.30 \mathrm{EJ}$ and $\mathrm{CO} 2$ emissions by $130.5-525.5 \mathrm{Mt}$ by 2025 .

However, the risks of digital fabrication are also recognised. Smith \& Hielscher (2015), see diminished scale inefficiencies, disruptions in waste collection and processing infrastructures as key issues. Drizo \& Pegan (2006) raise the issue of toxicity of rapid-protoyping materials and highlight the broad lack of knowledge on the life cycle impacts of additive manufacturing materials. In addition, the trade-offs between energy consumption, the crossover point at which additive technologies become less energy intensive, given the production volumes, needs to be fully understood.

While the promise and vision for RDM within makespaces, is compelling, there is limited understanding about what is being made. From the viewpoint of makespaces, some of the more 'needs-based' solutions Kohtala (2014) alludes to are mentioned in the literature, such as a device which can monitor milk quality for farmers or skin conditions in rural areas (Troxler, 2010). In contrast, Gebler et al (2014) summarise key markets for the uptake of 3D-printing to 2025 including: consumer products, aerospace, automotive, medical components and tooling. Importantly, this illustrates a divergence from the activities of makespace in general, from the sectors and goods forecasted to take up t.

Table 1. Defining (Re)distributed Manufacturing

\begin{tabular}{|l|l|}
\hline Source & Definition \\
\hline WEF & $\begin{array}{l}\text { “...enable...efficient use of resources, with less wasted capacity in centralized fac- } \\
\text { tories...to reduce the overall environmental impact of manufacturing: digital info } \\
\text { is shipped over the web rather than physical ....nd raw materials are sourced lo- } \\
\text { cally....reducing the energy...for transportation." }\end{array}$ \\
\hline BIS & $\begin{array}{l}\text { "...potentially disruptive impact on supply chains. The development of AM [addi- } \\
\text { tive manufacturing] faces unique technical challenges, but there are huge poten- } \\
\text { tial benefits including the possibility for more localised manufacturing and the } \\
\text { reduced need for part inventory." }\end{array}$ \\
\hline
\end{tabular}




\begin{tabular}{|l|l|}
\hline EPSRC & $\begin{array}{l}\text { "Technologies, systems and strategies that change the economics and organisation } \\
\text { of manufacturing, particularly with regard to location" }\end{array}$ \\
\hline $\begin{array}{l}\text { Kuhnle } \\
(2010)\end{array}$ & $\begin{array}{l}\text { "A decentralised approach could make production systems more flexible and } \\
\text { adaptable" }\end{array}$ \\
\hline
\end{tabular}

\subsection{Circularity: Circular Product Design \& Circular Business Models}

The terms circular product design and circular business models are derived from the overarching concept of a 'Circular Economy'. Circular product design, promoted by Bakker et al (2014) is achieved through designing for attachment and trust; durability; standardization and compatability; ease of maintenance and repair; adaptability and upgradability. This is because, to realise a circular economy, changes in both product design practices and business models are critical (see: Teece, 2010, Bakker et al, 2014). For example, Teece (2010), states that product development needs to iteratively inform developments in the business model. Moreover, Lehmann (2015) state that lack of understanding of the relationship between design and business models, for long-life products, is a barrier to business model innovation. Therefore, building linkages between design strategies and business models is important.

In simple terms, a business model is about the way you do business (Margretta, 2002) and therefore a circular economy can be viewed as a business model with a circular economy vision. Circular product design and circular business models, which are increasingly brought together through models and frameworks (see Costa et al; 2014, Prendeville \& Bocken, 2015).

\subsection{Literature Summary: Research \& Practice Gap}

The suggested benefits of additive technologies seem out of alignment with the observed characteristics of makespaces. For example, forecasts for market uptake of key technologies are linked to heavily regulated business-to-business sectors, whereas, the benefits observed (from the viewpoint of the makespaces) are around local solutions. Existing knowledge sees makespaces as powerful local connectors, with positive social impacts and the potential to build resilient local activities.

In addition, very little research has been undertaken that demonstrates how waste can be reduced through additive technologies and many questions remain about the environmental impacts of many materials used for RdM. In addition, Troxler (2010) states that most successful open hardware initiatives operate within market conditions and are not 'radically decentralized'. Another concern that appears to be overlooked in the literature, is how the on-demand nature, of a redistributed future, impacts on consumption levels in society, given the absence of any real basis to show that prosumption in and of itself, can overcome this. 


\section{$3 \quad$ Methodology}

The aim of the research is to explore interplay between makespaces, RDM and CE. In light of this the research question driving the research asks, "what is the role of makespaces in a sustainable redistributed manufacturing future? The research is based on six interviews designed to explore this question topics. The interviews are semistructured, conducted online, recorded and transcribed. The interviewees were provided with a participant information sheet in advance of the interview to describe the purpose and format. The interviewees were selected from an initial list of XX identified potential interviewees, based on expertise on the topic, experience of setting up and running makespaces and to cover a range of geographical contexts. Table 3 presents an overview of the interviews and Table 4 describes the semi-structured interview questions. Finally, the interviews were analysed thematically, within and across cases.

Table 2. Overview of Expert Interviews

\begin{tabular}{r|l|l|l}
\hline \hline & Interviewee Role & Date & Interviewee's Location \\
\hline 1 & Academic & 14.08 .2015 & Finland \\
\hline 2 & Makespace Founder & 5.08 .2015 & UK \\
\hline 3 & Makespace Founder / Academic & 22.06 .2015 & China \\
\hline 4 & Makespace Founder / Academic & 01.09 .2015 & UK \\
\hline 5 & Makespace Founder / Academic & 01.09 .2015 & Italy \\
\hline 6 & $\begin{array}{l}\text { Makespace Founder / Research- } \\
\text { er }\end{array}$ & 31.07 .2015 & Spain / Venezuela \\
\hline \hline
\end{tabular}

Table 3. Semi-structured Interview Guide

\begin{tabular}{c|l}
\hline \hline & Questions \\
\hline 1 & $\begin{array}{l}\text { Are you aware of the concept of redistributed manufacturing (RdM)? What do you } \\
\text { understand RdM to mean? Can you cite any examples? }\end{array}$ \\
\hline \hline
\end{tabular}




\begin{tabular}{c|l}
\hline \hline 2 & What do you think the importance of RdM is in terms of circularity? \\
\hline 3 & From your perspective, do you think Makespaces have a role in a RdM future? \\
\hline 4 & $\begin{array}{l}\text { What do you think RdM mean in terms of circularity? [a] What does this mean for the } \\
\text { future of manufacturing? }\end{array}$ \\
\hline 5 & What do you think this idea of circularity means in the context of Makespaces? \\
\hline 6 & What examples of circularity have you seen (in Makespaces), if any? \\
\hline 7 & $\begin{array}{l}\text { What do makespaces / the people of the MS need to develop / improve circular practice } \\
\text { (rationale for development of activities/tools)? }\end{array}$ \\
\hline 8 & $\begin{array}{l}\text { What is the role of technology in makespaces? What do these technologies mean in } \\
\text { terms of circularity? What are the (1) barriers (2) enablers (3) opportunities? }\end{array}$ \\
\hline 9 & $\begin{array}{l}\text { What is the role of people in makespaces? What do these people mean in terms of cir- } \\
\text { cularity? What are the (1) barriers (2) enablers (3) opportunities? }\end{array}$ \\
\hline 10 & What other characteristics would you say encourage a circular makespace? \\
\hline \hline
\end{tabular}

\section{$4 \quad$ Results \& Analysis}

This section presents the results of the interviews with an integrated thematic analysis.

\subsection{Redistributed Manufacturing: Terminology and Examples}

The concept of RDM was not familiar to all of the interviewees and during the interviews the term 'distributed manufacturing' was raised as more familiar phrase. Nonetheless, the research identified that (re)distributed is characterised by the following aspects:

- Open source, open design, sharing practice, knowledge and skills (as well as products)

- Reshoring manufacturing to the West

- Open, digital networks

- Collaborative and open innovation

- Enabled by diffusion of new technologies

- Personalisation and customisation

- Prosumption: bringing the custodian closer to manufacturing processes

- People-focused: not solely technology-centred / driven, but and also about local networks and social interactions 
However, one interviewee stated that RDM is really a 'partial phenomenon', widely discussed over the last ten years but with very little examples in practice. Those examples that were cited, illustrating more meso-level (urban activities such as agriculture and distributed energy projects) rather than directly relevant to production / manufacturing.

The respondents communicated that makespaces activities are predominantly protoyping and testing ideas and therefore are promising spaces for incubation and experimentation of new potential circular solutions and ideas. Also the potential of 3D printing in prototyping is still underexplored. While local production is a goal, it's not happening at any significant scale. Current outputs include components or prototypes that go on to be manufactured in a 'traditional' manufacturing environment. 'The maker movement talks so much about local production, but in reality that doesn't happen'. Despite this, interviewees which play a more active role within makespaces, responded favorably to the future prospects for batch production perceiving an increase in demand on the horizon. Examples cited as being close to, or moving towards redistributed, and circular / and sustainable, but not wholly redistributed in the sense that some characteristics of the approach is centralised, include:

- Fairphone, through its community-focus, ethical suppliers and material use

- Urban agriculture which is well developed at a city level e.g. Farm Shop Dalston

- Off-grid distributed energy solutions - energy is generated or stored by a variety of small, grid-connected devices referred to as distributed energy resources (DER) or distributed energy resource systems

- Will.i.a.m collaboration with Coca Cola to produce 'Ekocycle' which can process recycled PET (Coca Cola) bottles

- Filabot - sustainable $3 \mathrm{~d}$ printing. recycling parts to make new filaments which both saves money and reduces waste

- Solowheel, rapid versions developed, already in its 3rd generation after 6 months, in the loosely coupled manufacturing ecosystem of Shenzhen, China

- Dexta Robotics' Dexmo by Seeed Studios, the Shenzhen-based firm was founded as a bridge between Western makers and China's agile manufacturing ecosystem; aiming to design with manufacturing specs in mind; its Open Parts Library (OPL) catalogues compatible components for the most widely used parts in printed circuit board (PCB) designs.

\subsection{The Role of Makespaces in a Sustainable Redistributed Future}

From the interviews it is clear that makespaces are perceived to play a key role in an $\mathrm{RdM}$ future. This is perceived in a number of ways and some of these perspectives are reflected in the wider academic literature. 
- Through the implementation of shorter production loops to reduce waste and environmental impacts of transport.

- Additive technologies can facilitate repairability of products, by on-demand manufacturing of spare parts to extend the life of products. While this is broadly beneficial for society, in some cases repairing products may not be the best option, if more energy efficient options or solutions have come on the market.

- On the premise that makespaces encourage a broader demographic of society of people to make, and assuming people care more about things that they have had a role in making, thereby increasing the 'responsibility' of individuals and their attachment to products, by making the 'invisible visible'. Nonetheless, some interviewees communicated some scepticism about the realities of this happening at present, but also indicated that with the right support mechanisms (governmental incentives) such approaches could be a future reality.

- Open design practices, underpinned by sharing design files and solutions through digital networks, can address barriers to wider diffusion of CE, through the development of meaningful/viable open source (legal / business) framework, by overcoming intellectual property issues, but also by fostering greater supply chain transparency.

Nonetheless, broadly speaking, within makespaces, the understanding of the concept of circularity, and indeed wider sustainability, varies greatly. This is clear when comparing the activities of, as one cited example, Amersfoort Lab, which takes a deeply embedded sustainability approach (akin to industrial ecology) in comparison with other spaces which fail to implement basic waste separation facilities. Other visionary industrial ecology-like examples were cited, such as the ability to grow, harvest and process resources in localities close to makespaces such as growing oranges, the juice of which can in turn be used to feed the printer. This example also touches on the widespread perspective that the greatest potential for makespaces is seen in opportunities for incubation of creative start-ups, experimentation with new ideas and the space to test different approaches and innovative solutions. This relates to the capacity of makespaces to effectively educate, build and share skills and knowledge, which was consistently and enthusiastically communicated during the research.

\subsection{Challenges \& Opportunities}

Certain conditions limit the capacity for makespaces to implement RdM and CE principles. Similarly, many opportunities exist. Tables 4 and 5 summarise these findings. It is important to note that many of the challenges identified are not unique to makespaces as organisational entities, but rather reflect a wider body of knowledge on 
barriers to sustainability in industry and this literature should and can be drawn on to inform future interventions (Prendeville et al., 2010, O'Rafferty \& O'Connor, 2010).

Table 4. Challenges to Redistributed Manufacturing and Circular Economy from the viewpoint of Makespaces

\begin{tabular}{|c|c|}
\hline Challenges to RDM & Challenges to $\mathrm{CE}$ \\
\hline 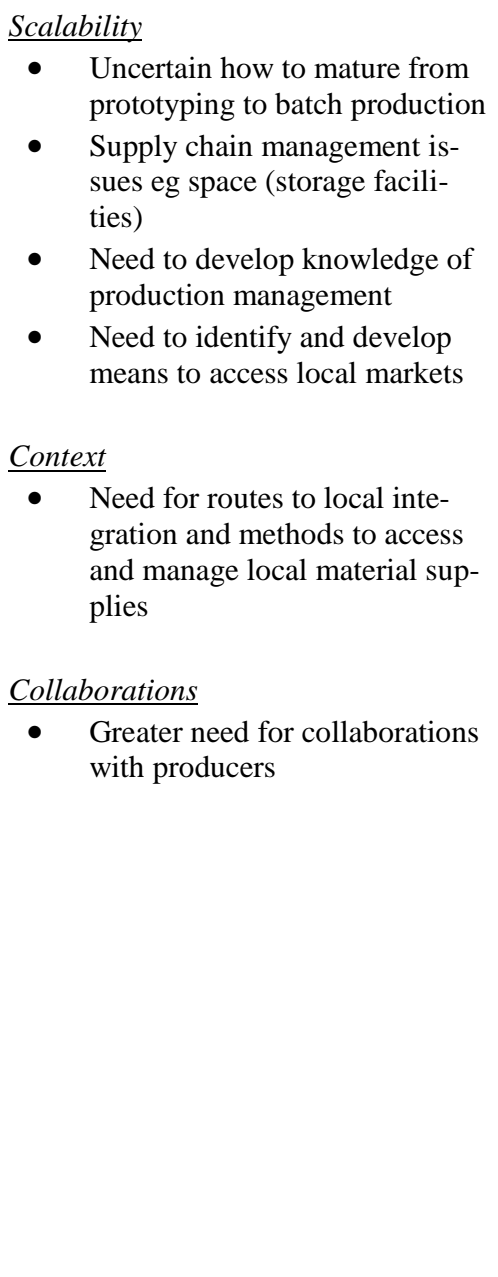 & $\begin{array}{l}\text { Know-how (lack of) } \\
\text { - } \quad \text { sustainable design } \\
\text { - } \quad \text { supply chain transparency } \\
\text { Leadership } \\
\text { - lack of aware 'eco-champions' to drive initia- } \\
\text { tives } \\
\text { knowledge-action gap } \\
\text { Organisational challenges } \\
\text { - } \quad \text { time poverty, money, personnel } \\
\text { decisions on materials and equipment, can be } \\
\text { guided by bureaucracy and the need to stream- } \\
\text { line processes } \\
\text { mission drift } \\
\text { Networks \& Resources } \\
\text { - } \quad \begin{array}{l}\text { lack of a central, connected, space to access } \\
\text { relevant knowledge and support }\end{array} \\
\text { - } \begin{array}{l}\text { invisibility and intangibility of issues } \\
\text { dated / inefficient technologies that are far } \\
\text { from state-of-the-art } \\
\text { lack of incentives (market demand and/or } \\
\text { governmental) for makers to develop sustain- } \\
\text { able/regenerative goods and services }\end{array} \\
\begin{array}{l}\text { Markets } \\
\text { able goods }\end{array} \\
\text { - }\end{array}$ \\
\hline
\end{tabular}


Table 5. Opportunities for Redistributed Manufacturing and Circular Economy from the viewpoint of Makespaces

\section{$\underline{\text { Culture }}$}

- Underlying ethos of openness and collaboration, which can be built on to diffuse and share best-practices, for example:

- Use of digital networks and sharing platforms provide an existing infrastructure through which to share knowledge, therefore, disseminating relatively simple technical knowledge on (for example) cutting practices to reduce waste, existence of local industrial symbiosis programmes and efficient ways of running machines is likely to have a strong positive effect.

- Experimentation is culturally intrinsic

- Natural investment in practical skills development and education / learning

Specialist Expertise \& Emerging Focus

Circular Economy and wider sustainability is a growing area of interest

Skills and knowledge for product repair and reverse-engineering of products through product tear-downs is common practice

\section{$\underline{\text { Social \& Environmental Sustainability }}$}

- Potential for deeply integrated social and environmental sustainability practices

- Evidence of industrial-ecology like approaches in combination with strong social, local networks

\section{Innovation, Prototypes \& Manufacturing}

- Potential for deeply integrated social and environmental sustainability practices

- Evidence of industrial-ecology like approaches in combination with strong social, local networks

- As places for experimentation, building circular practices into the earliest point of product development

\subsection{Overlaps between Makesapecs, CE and RdM}

Figure 1 summarises some of the key findings of the research, showing the current state of interplay between makespaces, CE and RdM. This figure is derived from the existing defintions of RdM and CE combined with the insights from the interviews. For example, it conveys the current role makespaces play in $\mathrm{CE}$, by contributing to repair. In addition, it shows how the strong social dimension seen within makesapces, could enrichen $\mathrm{CE}$, to move towards a deeper sustainability approach that brings both soci al and environmental imperatives together. This figure captures a picture of the research at a point in time, but could be adapted and built into a theoretical framework for future research. 


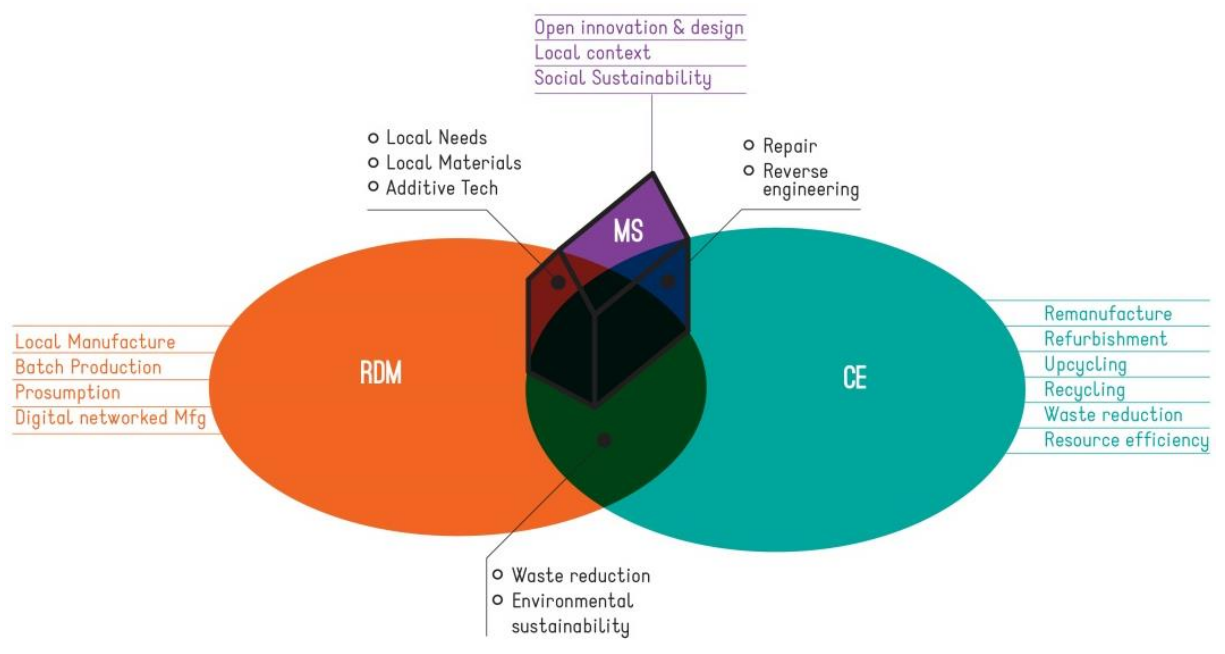

Fig. 1. Conceptualising Overlaps between CE, RDM and MS

\section{Conclusion}

This paper set out to discuss the role of makespaces in contributing to a circular economy through redistributed manufacturing. By identifying key challenges to overcome, and these are many and varied (see Tables 4), the findings of the research illuminate the need for a broad set of actions to support the professionalisation of makespaces, if these actors are to realistically play a role within a redistributed manufacturing ecosystem. In addition, the research uncovers a clear set of opportunities which can be harnessed (Table 5).

From the literature review, combined with the characteristics of RdM identified through the interviews, as well as the role of makespaces in CE, we have identified the current overlaps in these areas (Figure 1). This is a starting point for future research and captures a picture of insights developed through the research.

From the analysis and literature review, we forecast a rapid divergence of makespaces in the mid-term and this should be considered within any future support actions. This segmentation of makespaces is important, because, the research highlights that there is a risk of undermining the current value of makespaces many of which foster social cohesion in their local contexts. Indeed some examples have been cited, whose practices are likened to industrial ecology, a deep sustainability practice. Others, based on their mission, capacities and capabilities are potentially more suited to organised RdM activities.

Acknowledgements: This research was undertaken as part of the EPSRC-funded FMs RdM network project. 


\section{References}

1. Bakker, C., Den Hollander, M., van Hinte, E., Zijlstra, Y. (2014). Product that Last. Product Design for Circular Business Models. TU Delft Library, Delft, The Netherlands.

2. Bocken, N. M. P., P. Rana, and S. W. Short. (2015) "Value mapping for sustainable business thinking." Journal of Industrial and Production Engineering 32.1: 67-81.

3. Costa, F., Prendeville, S., Beverly, K., "Sustainable Product-service Systems for an Office Furniture Manufacturer: How Insights From a Pilot Study can Inform PSS Design." Procedia CIRP 30 (2015): 66-71.

4. Drizo, A. \& Pegna, J., 2006. Environmental impacts of rapid prototyping: an overview of research to date. Rapid Prototyping Journal, 12(2), pp.64-71.

5. European Commission (2013). Factories of the Future. Multi-annual Roadmap for the Contractual PPP under $\mathrm{H} 2020$.

6. European Commission (2014). Moving towards a circular economy. Available at: http://ec.europa.eu/environment/circular-economy/ (accessed October 2014).

7. Ellen MacArthur Foundation (2014). Ellen MacArthur Foundation - Rethink the Future. Available at: http://www.ellenmacarthurfoundation.org/ (accessed October 2015).

8. EPSRC (2013). Redistributed manufacturing workshop report.

9. Gebler, Malte, Anton JM Schoot Uiterkamp, and Cindy Visser. "A global sustainability perspective on 3D printing technologies." Energy Policy 74 (2014): 158-167.

10. Gershenfeld, N. "Fab." (2005).

11. Sabine Hielscher,Adrian Smith, Mariano Fressoli (2015) WP4 Case StudyReport:FabLabs,Report for the TRANSIT FP7 Project.

12. Kohtala, C. (2014) "Addressing sustainability in research on distributed production: an integrated literature review." Journal of Cleaner Production.

13. Kohtala, C. (2013) "Shaping sustainability in fab labs." Participatory Innovation Conference. Eds. H. Melkas, and J. Buur. Lahti: Lappeenranta University of Technology.

14. Lehmann, M., Bocken, N.M.P., Steingrímsson, J.G., Evans, S. 2015. Incorporating Design Thinking into Sustainable Business Modelling, Sustainable Design \& Manufacturing Conference, Seville, 12-14 April 2015

15. Magretta, J. (2002): Why Business Models Matter. In Harvard Business Review 80 (5), 86-92.

16. O' Rafferty, S., O' Connor, F., (2010) "Regional Perspectives on Capacity Building for Ecodesign" in Facilitating Sustainable Innovation through Collaboration, (p159-183). Springer Netherlands.

17. Prendeville \& Bocken, 2015 (forthcoming). Design for Remanufacturing and Circular Business Models. Ecodesign Conference 2-4th Dec. Tokyo, Japan.

18. Su, B.W., Heshmati, A., Geng, Y, Yu, X.M. (2013). A review of the circular economy in China: moving from rhetoric to implementation, Journal of Cleaner Production 42, 215227

19. Teece, D., (2010). Business Models, Business Strategy and Innovation. Long Range Planning 43 (2-3), 172-194.

20. Troxler, P. (2010). Open Design Now. Libraries of the Peer Production Era. Available at: http://opendesignnow.org/index.php/article/libraries-of-the-peer-production-era-peter-troxler/

21. Thakkara, J. (2010). Open Design Now. Into the Open. Available at: http://opendesignnow.org/index.php/article/into-the-open-john-thackara/

22. WEF (2015). Online. Accessed at: https://agenda.weforum.org/2015/03/emerging-tech-2015distributed-manufacturing/ 